(2) Open Access Full Text Article

REVIEW

\title{
New treatments for myasthenia: a focus on antisense oligonucleotides
}

This article was published in the following Dove Press journal:

Drug Design, Development and Therapy

9 January 2013

Number of times this article has been viewed

\section{Corrado Angelini' \\ Sara Martignago ${ }^{2}$ \\ Michela Bisciglia ${ }^{2}$}

'IRCCS S Camillo, Via Alberoni, Venice, Italy; ${ }^{2}$ Department of Neurosciences, University of Padova, Via Giustiniani 5, 35 I 28, Padova, Italy

Correspondence: Corrado Angelini

IRCCS S Camillo, Via Alberoni 70, 30I26,

Lido, Venice, Italy

Email corrado.angelini@unipd.it
Abstract: Autoimmune myasthenia gravis (MG) is a neuromuscular disorder caused by autoantibodies directed against the acetylcholine receptor (AChR). Current symptomatic therapy is based on acetylcholinesterase (AChE) drugs. The available long-term current therapy includes steroids and other immunomodulatory agents. MG is associated with the production of a soluble, rare isoform of AChE, also referred as the "read-through" transcript (AChE-R). Monarsen (EN101) is a synthetic antisense compound directed against the AChE gene. Monarsen was administered in 16 patients with MG and 14 patients achieved a clinically significant response. The drug is now in a Phase II study. Further investigations are required to confirm its long-term effects.

Keywords: myasthenia gravis, antisense oligonucleotides, acetyl cholinesterase, EN101

\section{Introduction}

Myasthenia gravis (MG) is an autoimmune disorder caused by autoantibodies binding to the nicotinic acetylcholine receptor (nAChR) on the postsynaptic membrane at the neuromuscular junction (NMJ), ${ }^{1}$ or, less frequently, to a muscle-specific tyrosine kinase (MuSK), an AChR-associated protein involved in clustering of AChRs and expressed in mature NMJ. ${ }^{2}$ In MG, the binding of autoantibodies to AChRs or MuSK results in an abnormal neuromuscular transmission and muscle weakness.

Acetylcholine (ACh) acts as the chemical messenger across the synaptic cleft between nerve fiber endings and postsynaptic muscle membrane: ${ }^{3}$ it is released into the synaptic cleft on nerve depolarization and rapidly diffuses across the gap to bind to acetylcholine receptors (AChRs) clustered in the endplate region. ${ }^{1}$ In healthy individuals, binding of $\mathrm{ACh}$ to its receptor results in the generation of an action potential necessary for muscle contraction. Binding of $\mathrm{ACh}$ to its receptor is a short-lived phenomenon: it rapidly fades away because of the decrease of its concentration within the synaptic cleft, due to diffusion processes and acetylcholinesterase (AChE) hydrolysis.

$\mathrm{AChE}$ inhibitors were among the earliest treatment options for MG and they remain one of the most widely used drug options. ${ }^{4}$ They are used as symptomatic treatment: slowing the degradation of ACh at the NMJ, they provide a temporary improvement in muscle strength. ACh inhibitors are used as adjunctive therapy in patients receiving immunomodulatory agents (such as steroids) that represent the usual long-term immunotherapy.

In this review, we present a summary of current treatment progresses in managing $\mathrm{MG}$, regarding the symptomatic therapy. We did a systematic PubMed search 
using the search terms "myasthenia gravis" and "antisense oligonucleotides" and appropriate citations were manually selected from the search results for inclusion in this review.

\section{Acetyl cholinesterase variants: the "read-through" transcript}

Acetylcholinesterase (AChE) is a complex of protein subunits, with an alternative promoter usage..$^{5}$ Its gene $(A C H E)$ is located in chromosome 7q22. Alternative splicing ${ }^{6}$ of exons at the $3^{\prime}$ end of the open reading frame of the AChE pre-mRNA gives rise to multiple isoforms in a stress-dependent and tissue-specific manner. ${ }^{7}$ In muscle, the principal transcript in physiological conditions is AChE-S, the synaptic form of AChE (also called "T", for "tailed"), ${ }^{8}$ which is formed by splicing exon 4 to exon 6 . The "read-through" isoform results from the continuous transcription from exon 1 to exon 6 , including intron $4 .^{9}$ These isoforms share a common catalytic domain: the ACh hydrolyzing efficacy between AChE-R and AChE-S is similar, but they differ in their C-terminal domain, which influences their form and localization. The AChE-R is a hydrophilic soluble monomer, due to its lack of the carboxyl-terminal cysteine, while AChE-S is a multimeric membrane-bound molecule, which associates with the postsynaptic membrane through a proline-rich (PRiMA) anchor. $^{10}$

Acute exposure to anticholinesterases shifts the splicing of the AChE pre-mRNA to the normally rare, soluble AChE-R variant, leading to its overproduction and accumulation, as a feedback response to reduce the cholinergic hyperactivity following an acute insult. ${ }^{11}$ Blood AChE-R levels increase after stress in healthy volunteers or after repeated cholinergic stimulation by AChE inhibitors, which both lead to AChE-R induction. $^{12}$

To reflect the alternative splicing of the AChE-R premRNA, the expression levels of the AChE-S multimeric isoform at synaptic cleft remain unmodified during cholinergic hyper stimulation. ${ }^{1}$ The rise of AChE-R levels attenuates the initial hyper excitation, enhancing the ACh hydrolysis and restoring the balance between the ACh and AChE levels, resulting in an effective restraint of the hyper cholinergic response, but data suggest that the continuous accumulation of AChE-R may prolong cholinergic impairment and cause morphological muscle changes. ${ }^{13}$

Overexpression of AChE- $\mathrm{R}$ is accompanied by neuromuscular pathology in mice chronically treated with low doses of AChE inhibitors, such as diisopropylfluorophosphonate (DFP), and AChE-R-related muscle weakness resembles the weakness syndrome that follows repeated or continuous exposure to agricultural anti-AChE pesticides or toxic warfare agents. ${ }^{14,15}$ Since AChE inhibitors remain one of the most widely used treatment options in $\mathrm{MG}$, they might modify the balance between the two AChE isoforms, thus AChE-R may be involved in the pathophysiology of the disease. ${ }^{13}$

\section{The role of AChE-R in myasthenia gravis}

In rats with experimental autoimmune myasthenia gravis (EAMG), high levels of AChE-R were found around the endplate and in serum. AChE-R accumulation in serum of EAMG and myasthenic patients may be the consequence of the imbalance between ACh and AChRs, with ACh prevailing on the number of receptors, as it occurs under treatment with AChE inhibitors. ${ }^{12}$ Slowing ACh catalysis results in an increased AChE-R production, due to a rapid feedback induction of AChE-R pre-mRNA. This leads to an increased ACh degradation and a subsequent limitation of the efficacy of AChE inhibitors. ${ }^{16}$ The effect of AChE inhibitors is actually short lasting, requiring oral drug administration every 4-6 hours.

The failure of AChE inhibitors in blocking AChE-R overexpression, thus preventing its muscle-weakening effects, may be due to their inefficiency to distinguish between the two AChE isoforms. ${ }^{17}$ Suppressing the AChE-R overexpression by targeting AChE pre-mRNA is an alternative in the treatment of $\mathrm{MG}$.

\section{Antisense oligonucleotides treatment in MG}

The use of antisense oligonucleotides in treating MG is largely based on pioneering research carried out by Soreq et $\mathrm{al}^{18}$ at the Hebrew University, Israel.

Antisense oligonucleotides are designed to selectively hybridize with AChE m-RNA: this activates RNAses with subsequent degradation of the mRNA-antisense complex and aborted synthesis of the encoded protein. Figure 1 shows the role of AChE-R, its mechanism of action and its interferences by antisense treatment. The antisense molecule then released binds to another strand of mRNA, thus creating a recycling mechanism. ${ }^{16}$

EN101, or Monarsen, is an antisense molecule 2'oxymethylated at its 3 '-terminal position, targeting at exon 2 of the AChE mRNA, a position common to all the AChE m-RNA splicing isoforms, ${ }^{18}$ yet AChE-R m-RNA appears to be more susceptible to destruction compared with AChE-S m-RNA, since the transcript is longer, less G-C rich, ${ }^{19}$ and devoid of polyribosomes. Monarsen, both by intravenous 


\section{A Myasthenia and anti-AChE treatment}
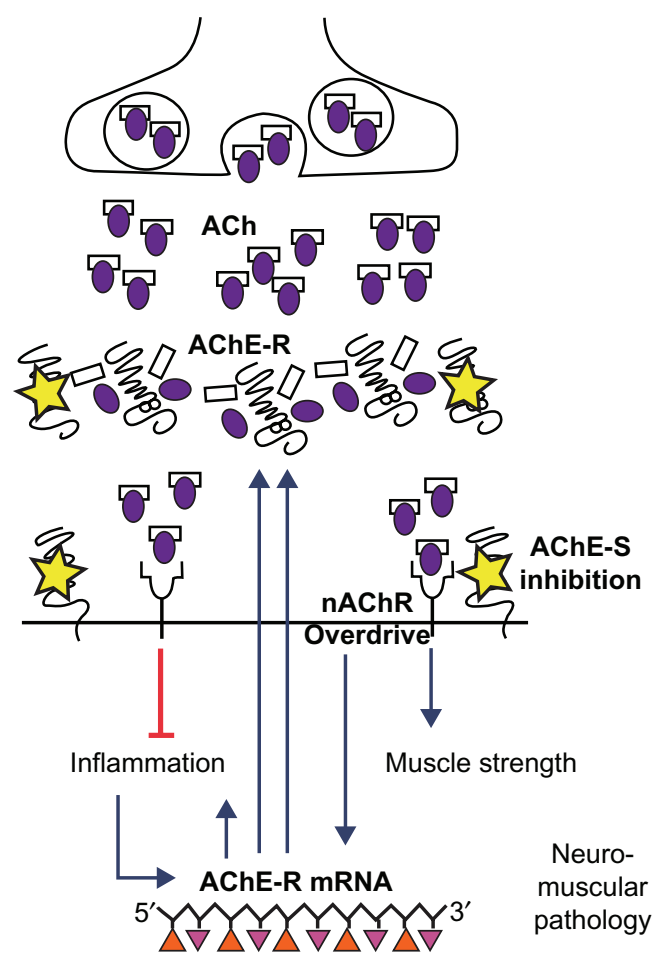

B Myasthenia and antisense treatment
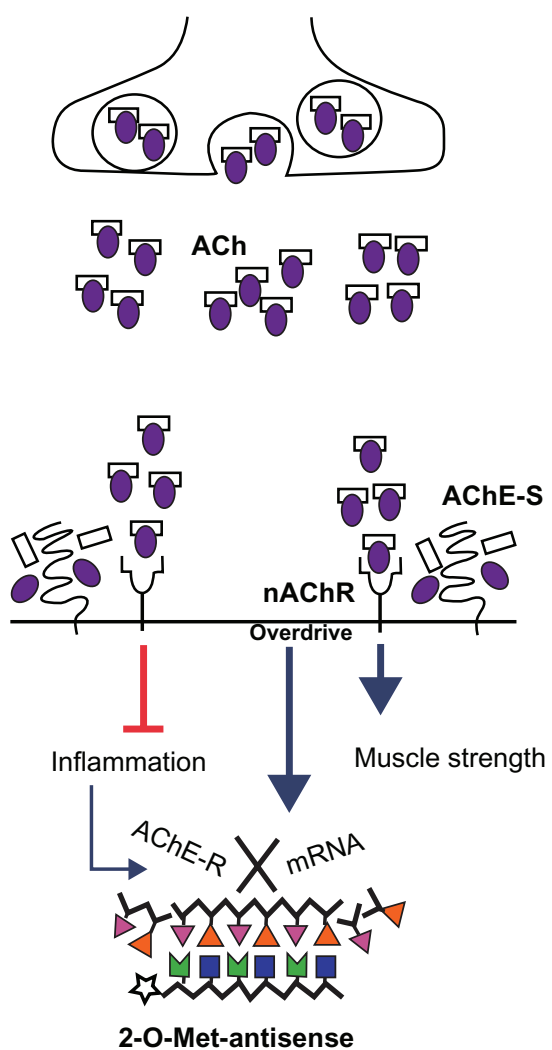

Figure I Schematic representation of AChE-R role and mechanism of action and its interferences by antisense treatment. (A) AChE inhibition leads to the overstimulation of $A C h R s$, with the subsequent induction of AChE-R pre mRNA. The rise of soluble AChE-R enhances ACh hydrolysis. This results in muscle weakness due to reduced cholinergic transmission to muscles, and induction of neuromuscular pathology. (B) 2-O-Met-Antisense treatment induces degradation of AChE-R mRNA, with an efficient reduction of the levels of $A C h E-R$.

Notes: ACh is hydrolyzed by AChE-S, but, without saturation of the synaptic cleft with AChE-R, a greater number of ACh molecules remain in the cleft and AChR is activated. Increased levels of ACh prevail on the muscle weakening and pro-inflammatory effect of AChE-R. AChE-R neuromuscular pathology is ameliorated. Copyright $(C$ 2006, Wiley. Adapted with permission from Dori A, Soreq H. Neuromuscular therapeutics by RNA-targeted suppression of ACHE gene expression. Ann N Y Acad Sci. 2006; 1082:77-90. ${ }^{17}$

Abbreviations: ACh, acetylcholine; AChE, acetylcholinesterase; AChE-R, rare "read-through" isoform of AChE; AChE-S, synaptic isoform of AChE; nAChR, nicotinic acetylcholine receptor.

or oral administration, has been shown to reduce AChE$\mathrm{R}$ in EAMG rats muscle and plasma, enhancing muscle strength as indicated by electromyography, in that it corrected the compound muscle action potentials (CMAPs) during repeated stimulation, in a dose-dependent manner, and induced improved task performance. ${ }^{12}$ Furthermore, in Phase Ib of an open-label study in patients with MG, orally administered Monarsen was shown to improve the Quantitative $\mathrm{MG}(\mathrm{QMG})$ score in 14 of the 16 patients examined. Inclusion criteria for the study were the following: $\mathrm{MG}$ with class II or higher-stage disease based on Myasthenia Gravis Foundation of America (MGFA) classification; and ACh-R-positive patients or patients with a clearly evident EMG neuromuscular function study. The patients had been on stable concomitant immunomodulatory treatment for at least 3 months, receiving at least $180 \mathrm{mg}$ of pyridostigmine per day, in stable clinical conditions. Patients with major muscle impairment or with exclusively mild ocular disease were excluded from the study.

Monarsen was orally administered for 4 days, after a 12-18-hour washout from pyridostigmine. Throughout the entire period, patients underwent a full check up and complete physical examinations including QMG score. Steroids treatment was continued during the whole period, while pyridostigmine was suspended and reintroduced when it was required. A follow-up assessment was made after 7, 14, and 28 days. Evaluation consisted of comparing baseline QMG (pretreatment) with QMG obtained during the experimental period. The QMG score summarizes 10 measurements: fatigue in each limb (4 measurements) and neck ( 1 measurement), swallowing rate (1 measurement), speech/counting (1 measurement), power in hands (2 measurements), and 
vital capacity on spirometry (1 measurement); plus three clinical observations: double vision, ptosis, and facial weakness. The maximum total QMG score is 39.

The overall mean percent of improvement from baseline was $46.5 \%$ (QMG score). More than $90 \%$ of the patients felt an improvement in symptoms during the treatment period. One patient failed to respond to Monarsen, remaining responsive to pyridostigmine, and was not included in the efficacy analysis. Adverse events were generally considered to be mild and they did not require suspension of the therapy. ${ }^{16}$ This study was not placebo-controlled. Neither the initial dose of pyridostigmine nor steroids/immunosuppressants were given, and, in contrast to animal trials, ${ }^{20,21}$ no plasma levels of AChE-R and AChR-S were given. Compared with pyridostigmine, Monarsen appeared to be more effective in enhancing muscle strength and providing a sustained QMG improvement, mainly in vital capacity and swallowing rate, over the course of the trial period. ${ }^{16}$

The latest publication regarding this compound is an announcement from Amarin Corporation (2009) about the encouraging results of an exploratory phase IIa multicenter, dose-ranging, crossover clinical trial with 31 participants. ${ }^{22}$ The study was performed in six centers in UK, Israel, and Serbia. The primary objective of the exploratory study was to assess the efficacy and safety of three doses of EN101 each given orally once daily for 1 week in patients with $\mathrm{MG}$, after a 1-week wash-out on pyridostigmine.

The final results of the study indicate that $10 \mathrm{mg}$, $20 \mathrm{mg}$, and $40 \mathrm{mg}$ of EN101 resulted in a statistically significant reduction in QMG score from a baseline of $11.8 \%$ $(P=0.001), 16.8 \%(P<0.001)$, and 20.3\% $(P<0.001)$, respectively. Furthermore, EN101 was shown to be safe and well tolerated. ${ }^{22}$

\section{AChE-R role in autoimmunity}

Recently the cholinergic anti-inflammatory pathway was identified, in which the stimulated vagus nerve, by releasing $\mathrm{ACh}$, reduces the secretion of pro-inflammatory cytokines: tumor necrosis factor (TNF) and interleukin (IL-1 $\beta$, IL-6, and IL-18). The mechanism is mediated by the homomeric $\alpha 7$ nicotinic AChR expressed on macrophages. ${ }^{23}$ Monarsen treatment suppressed the levels of stress-induced cytokines in cynomolgus monkeys ${ }^{20}$ and parallel results were found in EN101-treated mice, ${ }^{21}$ suggesting that the benefits of Monarsen might not be related exclusively to its role at the NMJ.

Considering the role of IL-1 $\beta$ in the pathophysiology of the disease, ${ }^{24}$ the reduction of the release of pro-inflammatory cytokines by increasing the peripheral Ach levels could partly explain the improvement in clinical scores under treatment with Monarsen: ${ }^{18}$ suppressing the inflammatory activation could antagonize the autoimmune destruction of AChR. Therefore, since steroids, which are the usual longterm therapy in MG, induce AChE-R pre-RNA, facilitating AChR accumulation, ${ }^{17}$ the use of Monarsen in managing $\mathrm{MG}$ could carry an additional benefit by recovering the cholinergic impairment that may be caused by steroid treatment.

\section{Conclusion}

Monarsen in an open trial was demonstrated to be more effective than pyridostigmine in improving QMG scores and was shown to have an overall safe profile. Antisense oligonucleotide-inhibiting AChE in treating MG showed positive effects in short-term oral administration, but further studies of the long-term effects are required.

The use of this drug needs to be validated in all forms of auto-immune MG, including MuSK MG, which is usually poorly responsive to the usual acetylcholinesterases therapy, ${ }^{25}$ and in which they could represent a viable alternative.

Another possible indication to be investigated is their potential use in the field of some congenital myasthenia: eventually, pyridostigmine-allergic or -intolerant patients may benefit from an alternative treatment.

\section{Disclosure}

The authors report no conflicts of interest in this work.

\section{References}

1. Drachman DB. Myasthenia gravis. N Engl J Med. 1994;330(25): 1797-1810.

2. Hoch W, McConville J, Helms S, Newsom-Davis J, Melms A, Vincent A. Auto-antibodies to the receptor tyrosine kinase MuSK in patients with myasthenia gravis without acetylcholine receptors antibodies. Net Med. 2001;7(3):365-368.

3. Hughes BW, Kusner LL, Kaminski HJ. Molecular architecture of the neuromuscular junction. Muscle Nerve. 2006;33(4):445-461.

4. Howard JF Jr, editor. Myasthenia Gravis: A Manual for the Health Care Provider. St Paul, MN: Myastehia Gravis Foundation of America; 2008. Available from: http://www.myasthenia.org/LinkClick.aspx?fileticket= S472fPAE1ow\%3D\&tabid=69. Accessed November 18, 2008.

5. Meshorer E, Toiber D, Zurel D, et al. Combinatorial complexity of 5 alternative acetylcholinesterase transcripts and protein products. $J$ Biol Chem. 2004;279:29740-29751.

6. Meshorer E, Bryk B, Toiber D, et al. SC35 promotes sustainable stressinduced alternative splicing of neuronal acetylcholinesterase mRNA. Mol Psychiatry. 2005;10:985-997.

7. Meshorer E, Soreq H. Virtues and woes of AChE alternative splicing in stress-related neuropathologies. Trends Neurosci. 2006;29(4): 216-224.

8. Massoulié J. The origin of the molecular diversity and functional anchoring of cholinesterases. Neurosignals. 2002;11:130-143.

9. Li Y, Camp S, Rachinsky TL, Getman D, Taylor P. Gene structure of mammalian acetylcholinesterase. Alternative exons dictate tissue-specific expression. J Biol Chem. 1991;266:23083-23090. 
10. Seidman S, Sternfeld M, Ben Aziz-Aloya R, Timberg R, Kaufer-Nachum D, Soreq H. Synaptic and epidermal accumulations of human acetylcholinesterase are encoded by alternative $3^{\prime}$-terminal exons. Mol Cell Biol. 1995;15:2993-3002.

11. Kaufer D, Soreq H. Tracking cholinergic pathways from psychological and chemical stressors to variable neurodeterioration paradigms. Curr Opin Neurol. 1999;12:739-743.

12. Brenner T, Hamra-Amitay Y, Evron T, Boneva N, Seidman S, Soreq H. The role of readthrough acetylcholinesterase in the pathophysiology of myasthenia gravis. FASEB J. 2003;17:214-222.

13. Lev-Lehman E, Evron T, Broide RS, et al. Synaptogenesis and myopathy under acetylcholinesterase overexpression. J Mol Neurosci. 2000;14:93-105.

14. Schwarz M, Loewenstein-Lichtenstein Y, Glick D, Liao J, Norgaard-Pedersen B, Soreq H. Successive organophosphate inhibition and oxime reactivation reveals distinct responses of recombinant human cholinesterase variants. Brain Res Mol Brain Res. 1995;31:101-110.

15. Kaufer D, Friedman A, Seidman S, Soreq H. Acute stress facilitates long-lasting changes in cholinergic gene expression. Nature. 1998;393: 373-377.

16. Sussman JD, Argov Z, McKee D, Hazum E, Brawer S, Soreq H. Antisense treatment for myasthenia gravis: experience with monarsen. Ann N Y Acad Sci. 2008;1132:283-290.

17. Dori A, Soreq H. Neuromuscular therapeutics by RNA-targeted suppression of ACHE gene expression. Ann N Y Acad Sci. 2006;1082: 77-90.
18. Soreq H, Seidman S. Acetylcholinesterase - new roles for an old actor. Nat Rev Neurosci. 2001;2:294-302.

19. Soreq H, Ben-Aziz R, Prody CA, et al. Molecular cloning and construction of the coding region for human acetylcholinesterase reveals a G + C-rich attenuating structure. Proc Natl Acad Sci U S A. 1990;87: 9688-9692.

20. Evron T, Moyal-Segal LB, Lamm N, Geffen A, Soreq H. RNA-targeted suppression of stress-induced allostasis in primate spinal cord neurons. Neurodegener Dis. 2005;2(1):16-27.

21. Pollak Y, Gilboa A, Ben-Menachem O, Ben-Hur T, Soreq H, Yirmiya R. Acetylcholinesterase inhibitors reduce brain and blood interleukin-1beta production. Ann Neurol. 2005;57(5):741-745.

22. Amarin: RNA therapy results announced to attract suitors [opinion]. PharmaWatch: Monthly Review. 2009;8(7):27-28.

23. Borovikova LV, Ivanova S, Zhang M, et al. Vagus nerve stimulation attenuates the systemic inflammatory response to endotoxin. Nature. 2000;405:458-462.

24. Huang D, Shi FD, Giscombe R, Zhou Y, Ljunggren HG, Lefvert AK. Disruption of the IL-1beta gene diminishes acetylcholine receptorinduced immune responses in a murine model of myasthenia gravis. Eur J Immunol. 2001;31:225-232.

25. Martignago S, Fanin M, Albertini E, Pegoraro E, Angelini C. Muscle histopathology in myasthenia gravis with antibodies against MuSK and AChR. Neuropathol Appl Neurobiol. 2009;35(1):103-110.
Drug Design, Development and Therapy

\section{Publish your work in this journal}

Drug Design, Development and Therapy is an international, peerreviewed open-access journal that spans the spectrum of drug design and development through to clinical applications. Clinical outcomes, patient safety, and programs for the development and effective, safe, and sustained use of medicines are a feature of the journal, which

\section{Dovepress}

has also been accepted for indexing on PubMed Central. The manuscript management system is completely online and includes a very quick and fair peer-review system, which is all easy to use. Visit http://www.dovepress.com/testimonials.php to read real quotes from published authors.

Submit your manuscript here: http://www.dovepress.com/drug-design-development-and-therapy-journal 